\title{
Some Observations in Curing of Thick Thermosetting Laminated Composites
}

\author{
Mehdi Hojjati and Suong V. Hoa \\ Concordia Center for Composites \\ Concordia University \\ Montreal, Quebec, Canada
}

\begin{abstract}
Curing of thick thermosetting laminated composites is studied, experimentally and numerically. Experiments were performed on a unidirectional 330-layer flat plate laminate in a bleed setup and a one-dimensional through-the-thickness situation. Both the temperature overshoot and incomplete through-the-thickness consolidation were observed. Owing to the low thermal conductivity of the bleeder plies in the bleed setup, the temperature distribution through-the-thickness is not symmetric. Therefore, the maximum temperature may not occur in the middle of the laminate (in this case, it occurred at the top of the laminate). A two-dimensional experiment was performed to reduce the temperature overshoot. Both the temperature overshoot and the cure cycle time were reduced in the two-dimensional experiment. Prebleeding technique was used to obtain uniform through-the-thickness consolidation. A thermochemical model combined with a resin flow (squeezed sponge model) equation were solved simultaneously in the simulation. The simulation results are in good agreement with the experimental results. It is shown that the bleeder plies increase the temperature overshoot. Since no bleeder plies are used in the final setup of the prebleeding technique and also complete compaction is achieved, it can be concluded that the prebleeding technique is the best method of fabrication for thick laminates.
\end{abstract}

\section{KEY WORDS}

composite, composite processing, thick laminate, curing, thermosetting resin

\section{INTRODUCTION}

Thick thermosetting laminated composites have found many applications in the construction, aerospace, and military industries. Fabrication of high-quality thick thermosetting laminate depends on proper choice of the processing parameters during curing. Time, temperature and pressure are the pertinent processing parameters in curing. A good choice of these three parameters can produce laminates which are fully cured, compacted, and of high quality.

Composites with low thermal conductivity as well as a reactive matrix, which produces heat, create a number of problems during processing of the thick laminates. The generated heat is slow to dissipate and may raise the inner part temperature to the critical level at which the laminate interior may be severely damaged. Another problem is the consolidation of a thick laminate. When the autoclave temperature is increased, the temperatures of the laminate at the inside and outside surfaces increase, the local viscosity decreases and consolidation begins at the bleeder sides. However, due to the low thermal conductivity of the laminate, heat cannot move fast inside the laminate. The interior viscosity remains high during the consolidation stage and complete through-the-thickness consolidation may not be achieved due to rein gelation.

The objective of this work is to study, experimentally and numerically, the curing of thick thermosetting laminates. A number of problems are identified and solutions are suggested. $A$ onedimensional through-the-thickness experiment was performed and two problems, the temperature overshoot at the second ramp of the cure cycle and 
incomplete through-the-thickness consolidation, were observed. A two-dimensional experiment was performed to reduce the temperature overshoot. Both the temperature overshoot and the cure cycle time are reduced in the two-dimensional experiment. Prebleeding technique was used to fabricate a thick laminate with uniform through-the-thickness consolidation. It is shown that owing to the presence of the bleeder plies, the temperature distribution throughthe-thickness is not symmetric and, therefore, maximum temperature overshoot may not occur in the middle of thick laminates. Simulation was performed and a good agreement between simulation and experiment was obtained. Based on the simulation and the experimental results, it can be concluded that the prebleeding technique is the best way to fabricate thick laminates.

\section{BACKGROUND}

Three different ways have been proposed to study the curing of thermosetting laminates: experiment, simulation and scaling (modeling). The common way to study the different processing parameters for thick laminates is to develop a mathematical model and then to do computer simulation $/ 1-8 /$. For a few cases (usually for thicknesses less than or equal to $5 \mathrm{~cm}$ ) $/ 1,4$, $5,6,8 /$, the experiment is performed and compared with the simulation results. After verification of the models and the simulation, a computer code is used to obtain the optimum processing parameters. Using nondimensional charts $/ 9 /$ as well as models $/ 10 /$ are the other ways proposed recently for the study of curing.

Loos and Springer / $1 /$ developed a one-dimensional simulation model for a flat laminate. Both heat transfer and resin flow were considered in their analysis. Temperature, degree of cure, resin flow, and void size were predicted as functions of autoclave pressure and temperature. They developed the sequential compaction model to describe the resin flow inside the laminate.

Bogetti and Gillespie /4/, Martinez $/ 5 /$ and Twardowski et al. /6/ addressed the curing of thick laminates. They studied just the heat problem. Only Twardowski et al. 16/ assumed the consolidation to be uniform through-the-thickness in their simulation. This may not be a correct assumption.

Gutowski /11/, Gutowski et al. /12,13/, Dave et al. /14-16/, Dave /17/ and Smith and Poursartip /18/ studied the consolidation and resin flow through the fiber bed. It was shown that the resin flow in composite processing can be modeled using the squeezed sponge model $/ 17,18 /$. Smith and Poursartip $/ 18 /$ showed that the sequential compaction model is essentially a special case of the squeezed sponge model.

The authors $17 /$ used simulation to study the onedimensional curing of thick laminates. The thermochemical and resin flow (squeezed sponge model) equations were solved simultaneously. It was shown that both the temperature overshoot and the uniform consolidation through-the-thickness should be considered during manufacturing in order to have a perfect part.

In this article, we describe the experiments and simulations performed to obtain a better understanding of the curing of thick laminates. In the experiment, mostly the bleed setup is used to obtain both heat transfer and resin flow during processing. In the simulation, the thermochemical models combined with the resin flow model (squeezed sponge model) are solved for one- and two-dimensional situations.

\section{EXPERIMENT}

The experimental apparatus and procedure used to measure the temperature and fiber volume fraction as well as the experimental results are described in this section. The studied material system is AS4/3501-6, a commercial graphite/epoxy prepreg from Hercules. The thickness of each ply is approximately $0.16 \mathrm{~mm}$ and it has 36 percent resin content by weight.

An experiment was performed to study the onedimensional curing of thick composites. Since both temperature overshoot and non-uniform through-thethickness compaction were observed, it was decided to study different ways to solve those problems. A twodimensional experiment was performed to show the heat transfer effect along the fibers in order to reduce the temperature overshoot inside the laminate. Prebleeding technique was used to achieve the uniform distribution of fibers through-the-thickness. Two 
experiments were performed to study the prebleeding effect on the fabrication of thick composites.

\subsection{One-Dimensional Experiment}

This experiment was performed to study the laminate behavior during curing under one-dimensional through-the-thickness assumptions. The heat and the resin were allowed to flow through-the-thickness, perpendicular to the fiber direction.

\section{Experimental tooling set-up}

A cross-sectional view through-the-thickness of the tooling set-up is shown in Figure 1. A unidirectional flat laminate, $7.6 \mathrm{~cm}$ by $7.6 \mathrm{~cm}$ and consisting of 330 layers, was produced by hand lay-up. Two K-type thermocouples were placed on top of the laminate (between layer 329 and layer 330) and in the middle of the laminate (between layers 165 and 166). The thermocouples were wrapped in a small layer of peel ply to prevent short-circuiting noise due to the graphite fiber conductivity. Four sides of the laminate were positioned against $4 \mathrm{~cm}$ wide ceramic blocks, acting as dams to prevent resin loss as well as to reduce heat flow through the edges. This arrangement closely resembles the one-dimensional through-the-thickness analysis. The laminate sides were wrapped tightly in a nylon film to help prevent resin loss. Eighteen layers of polyester bleeder materials supplied from Air-Tech International were placed on top of the laminate to

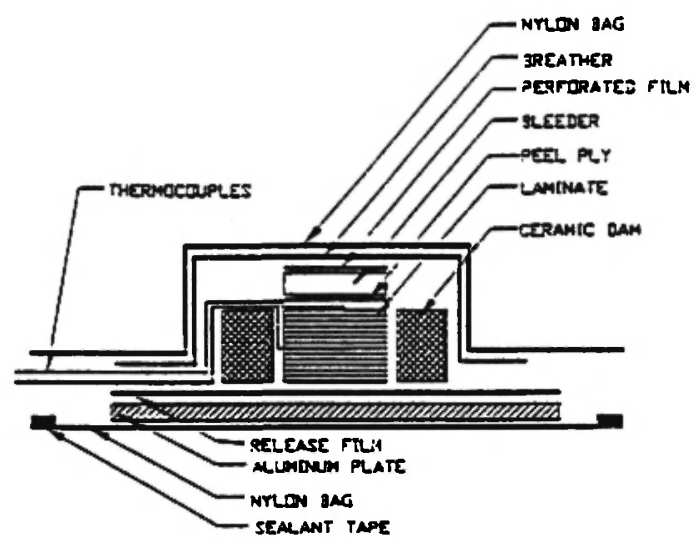

Fig. 1: Experimental tooling setup (bleed setup). absorb the resin. Two perforated nylon and a polyester breather material were placed on top of the bleeder to give the air an escape path when vacuum is applied. The assembly was covered with a nylon film and sealed. Vacuum was applied inside the vacuum bag. The whole assembly was placed in an autoclave. This type of set-up can be referred to as bleed processing since resin is intentionally removed during cure.

\section{Cure cycle}

A cure cycle based on the cure cycle recommended by the manufacture for thick parts of AS4/3501-6/6/ was applied. A pressure of $0.584 \mathrm{MPa}(85 \mathrm{psi}$ ) was applied inside the autoclave, with vacuum drawn on the charge. The temperature was raised to $115^{\circ} \mathrm{C}$. The laminate was then soaked for $120 \mathrm{~min}$ at this temperature based on the lagging thermocouple (the last thermocouple which indicates the target temperature is called the lagging thermocouple). The temperature was then raised to $150^{\circ} \mathrm{C}$ and the laminate soaked at this temperature for $90 \mathrm{~min}$ based on the lagging thermocouple. The final stage includes heating the laminate to $177^{\circ} \mathrm{C}$, with a $120 \mathrm{~m}$ min soak period based on the lagging thermocouple $/ 6 /$. The part was then allowed to cool to ambient temperature overnight before removal.

\section{Experimental results}

The temperature as a function of time was measured at the top layer (layer 329) and middle layer (layer 165) of the 330-layer laminate. Results of the temperature measurement are shown in Figure 2. The temperature on top of the laminate is higher than the temperature in the middle of the laminate. The insulating effect of the bleeder plies is the main reason for this phenomenon. Therefore, due to the presence of bleeder plies, the maximum temperature may not occur at the composite center. Since temperature at the bottom of the laminate (next to the aluminum plate) is shown to follow closely the temperature of the autoclave $/ 5 /$ and as evidenced in Figure 2, the temperature distribution through the thickness is nonsymmetric.

A uniform thickness was obtained (within an area of 4.5 by $4.5 \mathrm{~cm}$ ) at the center of laminate (in plane orientation). The final thickness at the center was 4.5 $\mathrm{cm}$. Fourteen layers of bleeder were completely filled 


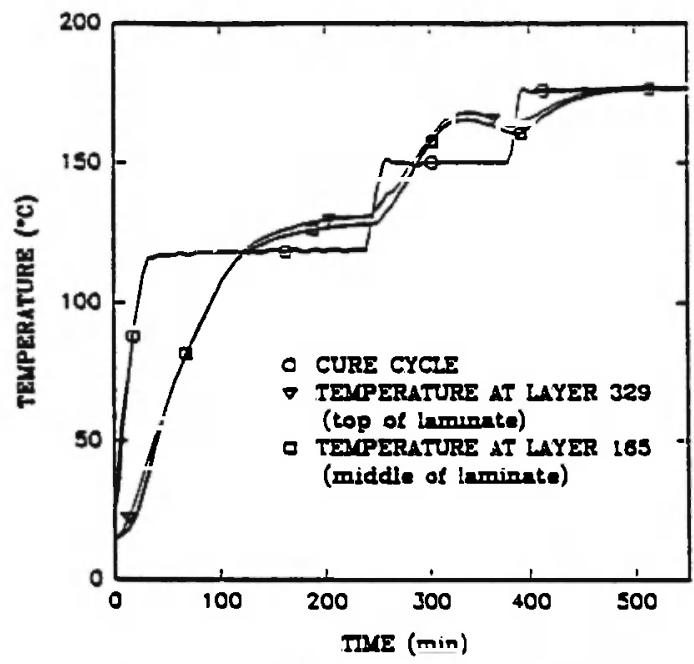

Fig. 2: Temperatures measured at different locations in the one-dimensional experiment (330layer laminate).

with resin. Some of the resin around the thermocouple location passed through all the bleeder layers and entered the breather.

The final part was cut to study the fiber distribution through-the-thickness. The laminate cross-section was polished using four sandpaper grades $(240,320,400$, and 600) and 1 micron alumina powder. The laminate photomicrographs at different locations are shown in Figure 3. There were a few void locations observed at the top ten layers as shown in Figure 4. Composite compaction at the top layers was better than at the bottom layers. There was nonuniform compaction and fiber volume fraction distribution, making the laminate imperfect.

The fiber volume fraction can be determined from the photomicrograph /19\%. This can be done by counting the number of fibers in a selected area and calculating the total fiber area from their average diameter. Using this technique, fiber volume fraction was obtained at the top, middle, and bottom of the laminate. In each photomicrograph, three regions of 2.5 $\mathrm{cm}$ by $2.5 \mathrm{~cm}$ were selected and the number of fibers (NF) was counted. One region was selected from a resin-rich area and one from a fiber-rich area. The third region was selected from the area where fiber and resin are distributed relatively uniformly. Results are shown in Table 1.
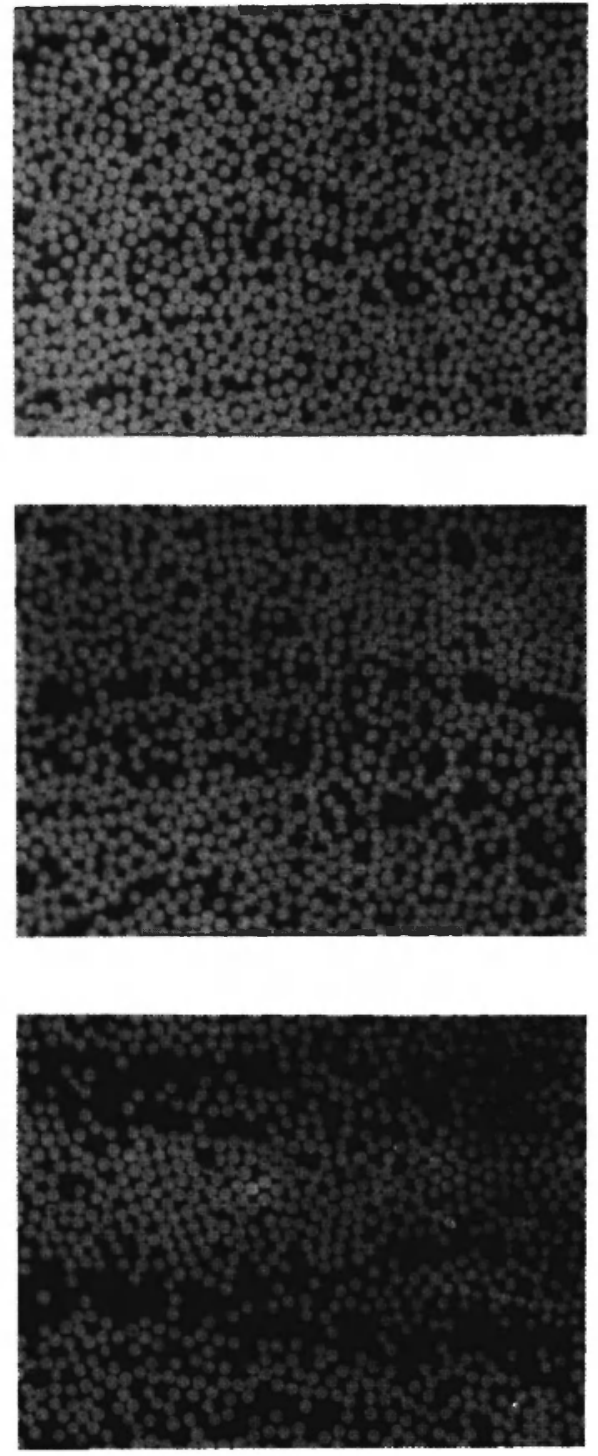

Fig. 3: Cross-section photomicrograph (399X) for the one-dimensional experiment and 330layer laminate. (a) Top of the laminate close to the bleeder side; (b) Middle of the laminate; (c) Bottom of the laminate close to the aluminum plate.

\subsection{Two-Dimensional Experiment}

This experiment was designed to show the effect of heat transfer through the sides of thick composite (sides perpendicular to the fiber direction in a unidirectional plate) during curing. Heat was allowed to flow through 


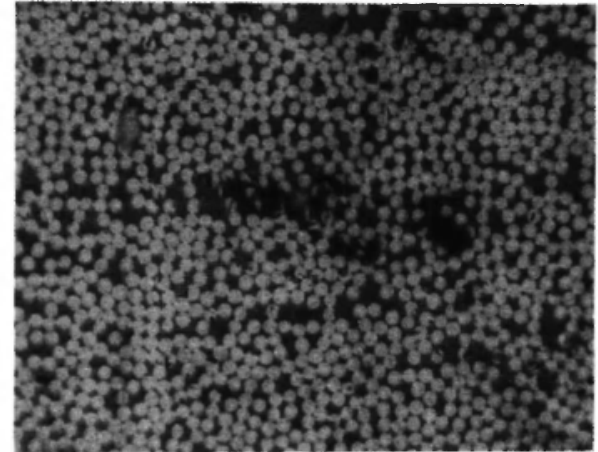

Fig. 4: Cross-section photomicrograph (399X) at the top ten layers of the laminate (onedimensional experiment and 330-layer laminate).

the thickness and through the two other sides. It was intended to allow the resin to flow only through the thickness.

\section{Experimental tooling set-up}

The tooling set-up used was the same as in the onedimensional experiment. The only difference was the use of aluminum plates at two edges instead of the ceramic insulation. These two aluminum plates were located perpendicular to the fiber directions, allowing heat to travel along the fiber directions. Note that the thermocouples should be located perpendicular to the fiber direction. The cure cycle for the one-dimensional experiment described above was used for this experiment as well.

\section{Experimental results}

The temperature as a function of time was measured at two different locations (top and middle) inside a 330ply laminate. The results of the temperature measurement are shown in Figure 5. As in the one-dimensional case, the temperature at the top is larger than the temperature in the middle. The maximum temperature may not occur at the laminate center. Comparison between Figures 2 and 5 shows that heat can flow much faster inside the laminate in the two-dimensional case. In the first dwell of the cure cycle, the temperature based on lagging thermocouple reached $116^{\circ} \mathrm{C}$ in $85 \mathrm{~min}, 35$
Table 1

Fiber volume fraction at different locations (onedimensional experiments and 330-layer laminate).

\begin{tabular}{|c|c|c|c|c|c|}
\hline \multicolumn{2}{|c|}{ Top } & \multicolumn{2}{c|}{ Middle } & \multicolumn{2}{c|}{ Bottom } \\
\hline NF & $v_{f}$ & NF & $v_{f}$ & NF & $v_{f}$ \\
\hline 60 & 0.59 & 54 & 0.53 & 45 & 0.44 \\
66 & 0.65 & 58 & 0.57 & 56 & 0.55 \\
69 & 0.68 & 67 & 0.66 & 66 & 0.65 \\
\hline Ave. & 0.64 & Ave. & 0.58 & Ave. & 0.55 \\
\hline
\end{tabular}

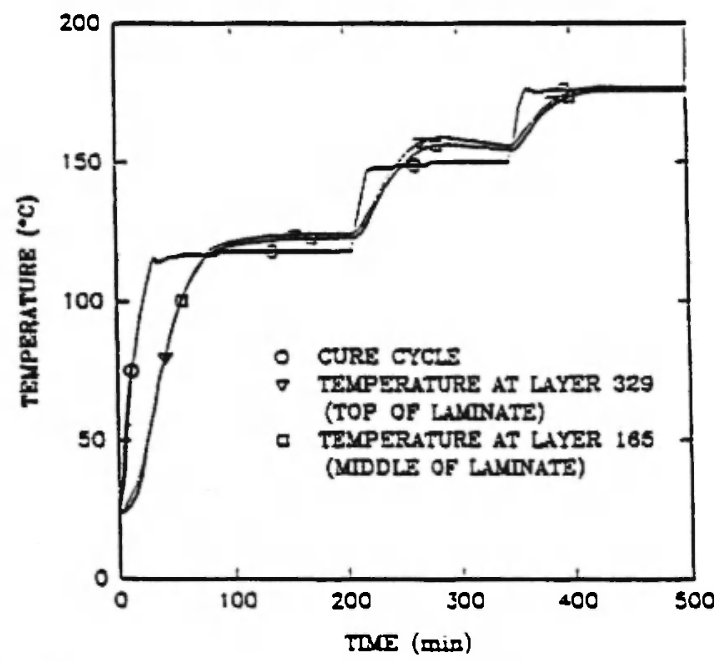

Fig. 5: Temperatures measured at different locations in the two-dimensional experiment (330layer laminate).

min faster than in the one-dimensional case. The high thermal conductivity of the composite along the graphite fibers causes heat to flow much faster. The temperature overshoot in the second dwell of the cure cycle is lower than in the one-dimensional case. Therefore, two-dimensional curing reduces the cure cycle time as well as the temperature overshoot in the second dwell period of cure cycle.

It was intended to let the resin flow only throughthe-thickness. However, due to the small gap between the aluminum plate and the laminate sides, some resin was pushed out through these gaps. All eighteen layers of the polyester bleeder were full of resin. 


\subsection{Prebleeding.Experiment}

While the cure cycle recommended for a thick laminate can solve the temperature overshoot problem (Figures 2 and 5), complete through-the-thickness consolidation may not be achieved (Figure 3). In the prebleeding experiment, the thick laminate is divided into a number of sublaminates. Each sublaminate is subjected to the consolidation cure cycle to produce the fully-compacted and partially cured sublaminates. Those sublaminates are put together to make up the thick laminate. The thick composite is exposed to a second cure cycle to complete the cure process. Therefore, a uniform fiber distribution is achieved.

\section{Experimental tooling set-up}

Fabrication of thick laminates using the prebleeding technique consists of two steps, prebleeding and final curing. Ten sublaminates, each consisting of 32 layers, were prepared by hand lay-up. The bleed setup (Figure 1) was used for the prebleeding step. Six layers of polyester bleeder were used. The sides of the sublaminates were wrapped tightly with Teflon film and then placed against the ceramic dams. All ten sublaminates were placed inside the autoclave simultaneously and the prebleeding cure cycle was applied. After completion of the prebleeding stage, those ten sublaminates were put together to fabricate a thick composite. A K-type thermocouple was placed in the middle of the laminate. Again the laminate sides were wrapped tightly with Teflon film to prevent any resin loss. No-bleed setup (identical to bleed setup except that no bleeder plies are used on top of the laminate) was used for this stage. None of the resin is intentionally removed during cure in the no-bleed setup.

\section{Cure cycle}

Two cure cycles were designed based on the cure cycle recommended by the manufacturer. The first cure cycle was applied to the prebleeding stage. A pressure of $0.584 \mathrm{MPa}$ ( $85 \mathrm{psi}$ ) was applied and vacuum was drawn on the bagged charge. The temperature was raised to $116^{\circ} \mathrm{C}$ and sublaminates were soaked for $70 \mathrm{~min}$ at this temperature. The pressure and vacuum were released and the charge was allowed to cool down to room temperature.
The second cure cycle was applied for final curing of the thick laminate. Again, $0.584 \mathrm{MPa}$ pressure was applied, with vacuum drawn on the charge. The temperature was increased to $116^{\circ} \mathrm{C}$ and the laminate was soaked for $60 \mathrm{~min}$ at this temperature based on the lagging thermocouple. The temperature was increased to $150^{\circ} \mathrm{C}$. The charge was soaked at this temperature for $90 \mathrm{~min}$ based on the lagging thermocouple. The temperature was then increased to $177^{\circ} \mathrm{C}$. The part was soaked at this temperature for $120 \mathrm{~min}$, again based on the lagging thermocouple.

\section{Experimental results}

Temperature was measured in the middle of the laminate during the final cure. The result is shown in Figure 6. Temperature overshoot is less as compared to full-bleed setup (Figure 2). There are three reasons for the decrease in the temperature overshoot. First, all layers are completely compacted in the prebleeding stage and, therefore, less resin remains inside the laminate during final cure, producing less heat. The second reason is the thickness of the laminate. Since compaction has already been done on all layers, the final thickness of the 320-layer laminate is smaller. Finally, application of the no-bleed setup during final curing and eliminating the thick bleeder layers from the setup help the heat to dissipate faster from the center region of the laminate.

All bleeder plies were full with resin during the prebleeding experiment. The measured thickness of the

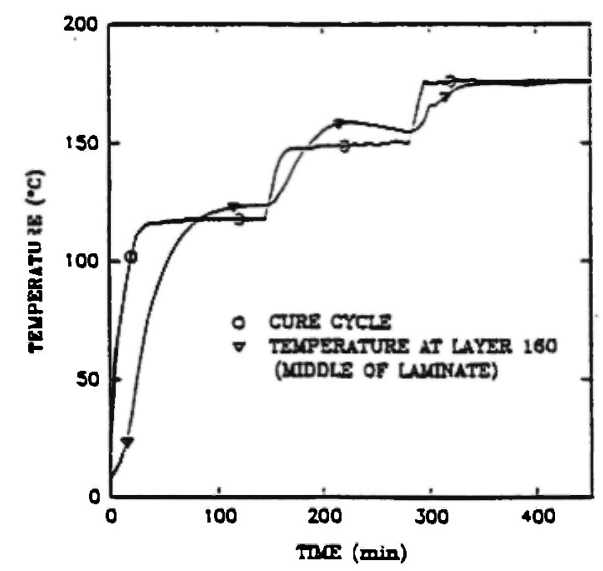

Fig. 6: Temperatures measured in the middle of the 320-layer laminate-prebleeding experiment. 


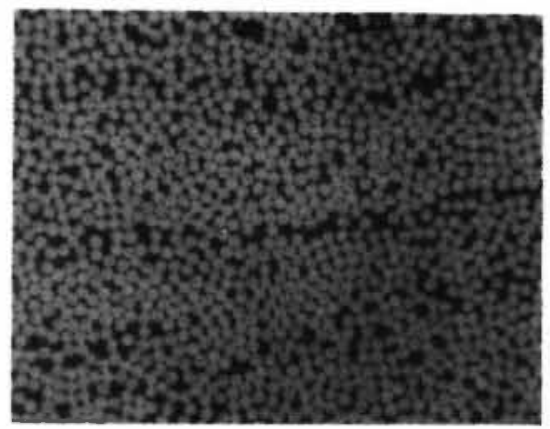

a

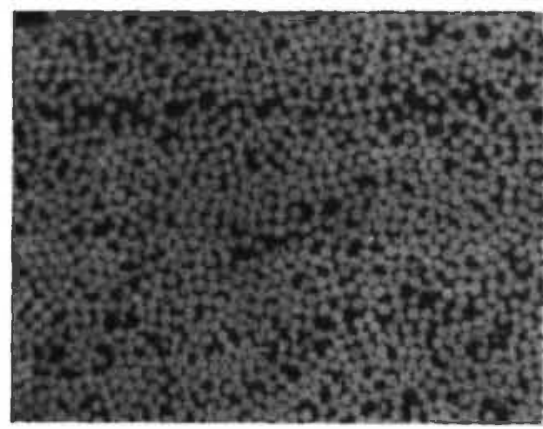

b

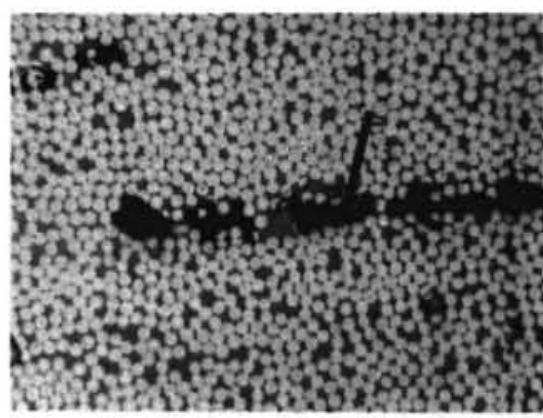

Fig. 7: Cross-section photomicrographs (399X) for the prebleeding experiment and 320-layer laminate. (a) Top of the laminate close to the bleeder; (b) Bottom of the laminate close to the aluminum plate; (c) voids in resin-rich areas.

sublaminates after the prebleeding stage was between $4.55 \mathrm{~mm}$ and $4.60 \mathrm{~mm}$. It was expected to have sublaminates with a thickness around $3.8 \mathrm{~mm}$. Since the fiber shows spring-like behavior during the dwell period of the prebleeding cure cycle, the resin flows out and the fibers start to contact each other. The autoclave pressure is transferred to the fibers and the resin pressure drops. At the end of the dwell period, the resin is partially cured. However, due to the high temperature $\left(116^{\circ} \mathrm{C}\right)$, the resin is still liquid. Releasing pressure and vacuum at this time causes the fibers to move upward due to their springback behavior. Therefore, the sublaminate thicknesses were greater than expected.

The final thickness after complete curing was 38 $\mathrm{mm}$. The laminate was cut and prepared for microscope inspection. The photomicrographs at different locations are shown in Figure 7. Examination of the cross-section under the microscope showed that the fibers are uniformly distributed through-the-thickness of the 320layer laminate with a small resin-rich area. However, there were a few voids observed, especially in the resinrich area (Figure 7). Examining the fabrication process, two problems were found in the prebleeding stage. Six layers of the polyester bleeder absorb too much resin, decreasing the resin pressure rapidly. There was moisture present in the resin during the prepreg production and the lay-up procedure. At a high temperature, the resin should be under sufficient pressure to prevent nucleation of dissolved water in the resin on the graphite fiber surface. This phenomenon has been well described by Dave et al. /14/. Since the resin pressure dropped too much, voids were formed.

Releasing pressure and vacuum at the end of the dwell period of the prebleeding cure cycle was the next problem. The fibers move upward due to their springback behavior and air gets into the sublaminates.

The measured fiber volume fraction at the top and bottom of the laminate are given in Table 2 .

\section{Modified fabrication procedure}

To fabricate a void-free thick laminate, a new experiment was designed and performed. Six sublaminates, each consisting of 20 layers, were made

\section{Table 2}

Fiber volume fraction at different locations (prebleeding experiments and 320-layer laminate)

\begin{tabular}{|c|c|c|c|}
\hline \multicolumn{2}{|c|}{ TOP } & \multicolumn{2}{c|}{ BOTTOM } \\
\hline NF & $\nu_{f}$ & NF & $\nu_{f}$ \\
\hline 70 & 0.69 & 74 & 0.73 \\
68 & 0.67 & 69 & 0.68 \\
67 & 0.66 & 67 & 0.66 \\
\hline Ave. & 0.67 & Ave. & 0.69 \\
\hline
\end{tabular}


by hand lay-up. All six sublaminates were prepared by bleed setup (Figure 1). Two bleeder plies were used for each sublaminate. All sublaminates were subjected to the modified prebleeding cure cycle. This prebleeding cure cycle was the same as above, except that the pressure and vacuum were held until the charge cooled down (around $30^{\circ} \mathrm{C}$ ). All six modules were put together and laminate sides were wrapped tightly in Teflon film. No-bleed setup was used to prepare the laminate for final curing.

The laminate cross section was examined through the microscope. Photomicrographs of the cross section are shown in Figure 8. The fiber distribution was uniform throughout the laminate. Some resin-rich areas were observed (Figure 8). No voids were observed. Therefore, a laminate with uniform fiber distribution through-the-thickness and no voids were obtained.

\section{THEORY}

To study the cure process, the development of mathematical models to describe the fundamental mechanisms involved, such as heat transfer, exothermic chemical reaction, and resin flow, is required. Such models are needed to relate the temperature and pressure applied during the cure to the thermal, chemical, and physical process occurring inside the material. Four models which are used to obtain governing equations describing the fundamental mechanism in curing are the heat model, kinetic model, viscosity model, and flow model. The first three models, referred to as the thermochemical model, yield the temperature, the degree of cure, and the viscosity. The fourth model gives the resin pressure, the resin flow out of the composite, and the composite fiber volume fraction. The governing differential equations describing different models are coupled together and should be solved simultaneously.

\subsection{Mathematical Models}

Fourier's heat conduction equation with an internal heat generation term is used to obtain the temperature solution. Energy transfer by convection is assumed to be negligible. The governing equation for two-
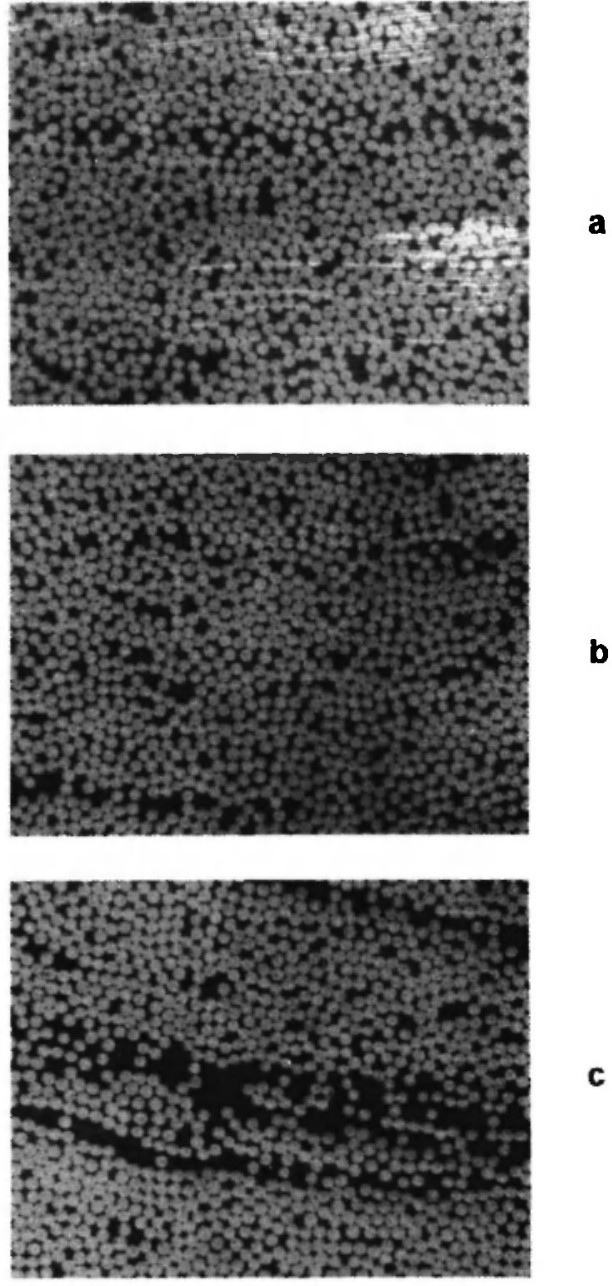

C

Fig. 8: Cross-section photomicrographs (399X) for the prebleeding experiment and 120-layer laminate. (a) Top of the laminate; (b) Bottom of the laminate; (c) Resin-rich area.

dimensional analysis (Figure 9) can be written as /20/

$$
\frac{\partial}{\partial x}\left(\dot{k}_{z} \frac{\partial T}{\partial x}\right)+\frac{\partial}{\partial z}\left(\dot{\kappa}_{z} \frac{\partial T}{\partial z}\right)+g=\rho c_{p} \frac{\partial T}{\partial t}
$$

where $x$ and $z$ are independent variables and are shown in Figure 9. $k_{x}$ and $k_{z}$ are the laminate thermal conductivities along the $x$ and $z$ directions, respectively. $\dot{g}$ represents the internal heat generation due to the exothermic chemical reaction inside the resin. $\rho$ is the laminate density and $c_{p}$ is the specific heat of the laminate. $T$ and $t$ are absolute temperature and time, 

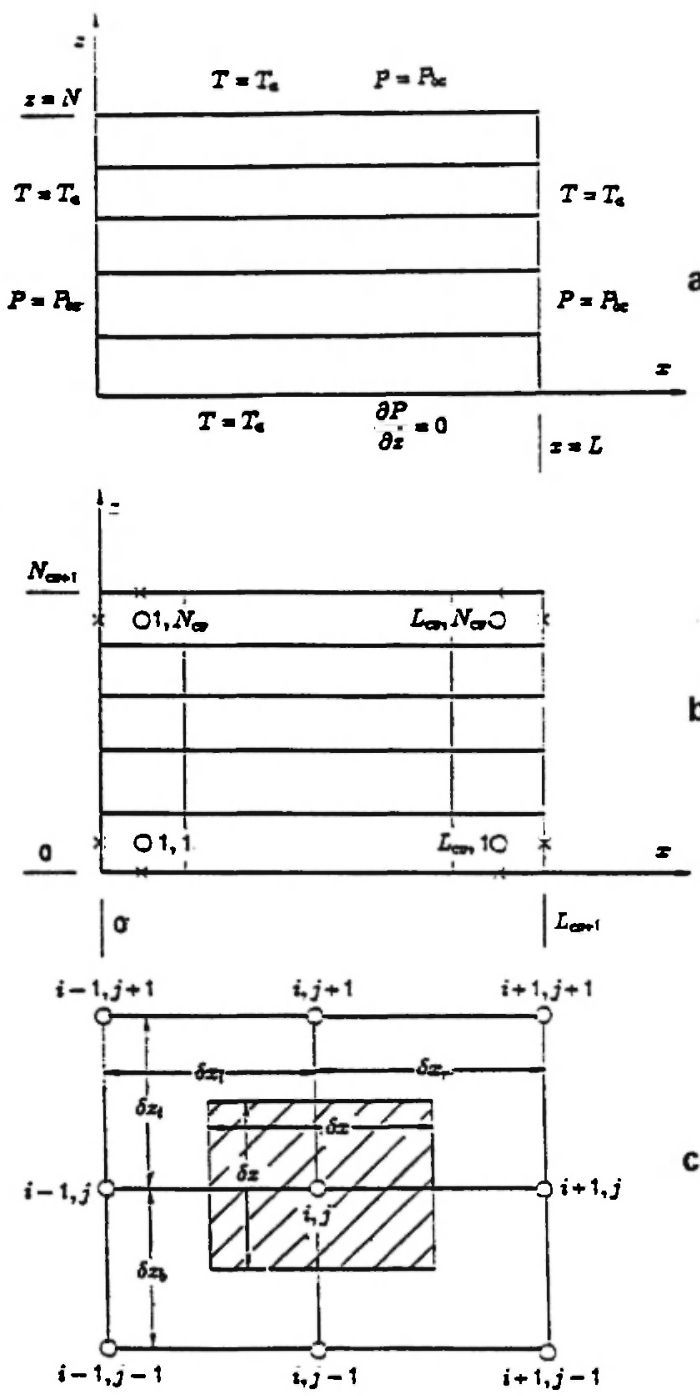

Fig. 9: Two-dimensional analysis. (a) Composite geometry and boundary conditions; (b) Computational domain; (c) Control volume.

respectively.

The initial conditions are

$$
\begin{array}{cl}
T(x, z, 0)=T_{0}, & 0 \leq x \leq L \\
\propto(x, z, 0)=0 & 0 \leq z \leq N
\end{array}
$$

$T_{O}$ is the laminate initial temperature. $L$ and $N$ are the laminate length and thickness (Figure 9), respectively. For the flat plate composite, the boundary conditions are

$$
\left.\begin{array}{l}
T(0, z, t)=T(L, z, t)=T_{a}(t) \\
T(x, 0, t)=T(x, N, t)=T_{a}(t)
\end{array}\right\}^{t \geq 0}
$$

$T_{a}$ is the autoclave temperature and can be either a constant or a function of time.

The laminate consists of both fiber and resin. The chemical reaction inside the resin is the only source of heat generation inside the composite. Therefore, the heat generation term used in Equation (1) should be calculated as

$$
\dot{g}=\rho_{\tau}\left(1-\nu_{f}\right) \frac{d \alpha}{d t} H_{R}
$$

where $\dot{\boldsymbol{g}}$ is the rate of heat generation per unit volume. $\rho_{r}$ is the resin density and $v_{f}$ is the fiber volume fraction. $\alpha$ is the degree of cure and $H_{R}$ is the total heat of reaction of the resin. To calculate $\dot{g}$, an expression b for the rate of degree of cure $\left(\frac{d \alpha}{d t}\right)$ is required. This expression is usually called the kinetic equation. Graphite/epoxy AS4/3501-6 was used for the simulation and experiments. The kinetic equation for the Hercules 3501-6 resin can be expressed as /21/

$$
\frac{d \alpha}{d t}= \begin{cases}\left(K_{1}+K_{2} \alpha\right)(1-\alpha)(0.47-\alpha) & \alpha \leq 0.3 \\ K_{3}(1-\alpha) & \alpha>0.3\end{cases}
$$

where

$$
\begin{aligned}
& K_{1}=A_{1} \exp \left(\frac{-\Delta E_{1}}{R T}\right) \\
& K_{2}=A_{2} \exp \left(\frac{-\Delta E_{2}}{R T}\right) \\
& K_{3}=A_{3} \exp \left(\frac{-\Delta E_{3}}{R T}\right)
\end{aligned}
$$

and $A_{1}, A_{2}$, and $A_{3}$ are pre-exponential factors. $\Delta E_{1}, \Delta$ $E_{2}$, and $\Delta E_{3}$ are the activation energies, and $R$ is the universal gas constant. Equations (1) and (4) subjected to the mentioned initial and boundary conditions (Equations (2) and (3)) need to be solved to obtain the temperature and the degree of cure distribution inside the composite.

Coupling between the thermochemical model and the resin flow model is realized through the viscosity model. The viscosity $\mu$ of thermoset resins decreases with increasing temperature and increases with increasing degree of cure $\alpha$. Since both the viscosity and degree of cure are functions of temperature and time, a relationship between $\mu$ and $\alpha$ can be established /21/. The following expression can be used to describe 
the resin viscosity $/ 21 /$

$$
\mu=\mu_{m} \exp \left(\frac{U}{\pi \tilde{I}}+\kappa \alpha\right)
$$

where $\mu_{\infty}$ and $\kappa$ are constants and $U$ is the activation energy for viscosity.

The squeezed sponge model is used to describe resin flow through the laminate $/ 11,18 /$. It is assumed that the autoclave pressure is constant. The governing differential equation describing the one-dimensional consolidation and two-dimensional flow (Figure 9) can be expressed as $/ 15,17 /$

$$
\frac{\partial}{\partial \bar{x}}\left(\frac{s_{x}}{\mu} \frac{\partial P}{\partial x}\right)+\frac{\partial}{\partial z}\left(\frac{s_{z}}{\mu} \frac{\partial P}{\partial z}\right)=m_{\nu} \frac{\partial P}{\partial t}
$$

where $P$ is the resin pressure, $s_{x}$ and $s_{z}$ are the laminate permeabilities in the $x$ and $z$ directions, respectively. $m_{v}$ represents the coefficient of the volume change determined by experiment $/ 7 /$.

The initial condition is

$$
P(x, z, 0)=P_{a}\left\{\begin{array}{l}
0 \leq x \leq L \\
0 \leq z \leq N
\end{array}\right.
$$

where $P_{a}$ is the autoclave pressure. Boundary conditions are

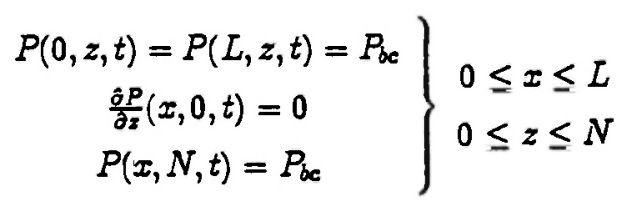

where $P_{b c}$ is the bag pressure.

\subsection{Method of Solution}

Four models are used to describe the composite behavior during curing. Equations (1), (5), (9), and (10), describing various phenomena inside the composite, should be solved simultaneously to obtain the different parameters during the cure process. There is no closed form solution for this system of coupled equations. A numerical technique is required to solve this system of equations. In general, numerical techniques can be used to solve the problem with complex geometry and boundary conditions. Moreover, the numerical techniques can also account for nonlinear stress-strain behavior of the porous medium and for varying thermal conductivity, density, specific heat, permeability, applied temperature, and applied pressure during the cure process.

The Control-Volume formulation combined with the Alternating Direction Explicit (ADE) method are used to discretize Equations (1) and (10) /8/. This type of discretization consists of two steps: forward sweep and backward sweep. Suppose $u_{l, j}$ is the pseudotemperature solution of equation (l) in the forward sweep. The final expression for $u_{t, f}$ at time step $t+\delta t$ for an interior node during the forward sweep can be derived as $\mathbf{8} /$

$$
\begin{gathered}
\left(1+a_{2}+a_{4}\right) u_{i, j}^{n+1}=\left(1-a_{1}-a_{3}\right) u_{i, j}^{n}+ \\
a_{1} u_{i+1, j}^{n}+a_{2} u_{i-1, j}^{n+0}+a_{3} u_{i j+1}^{n+n}+a_{4} u_{i, j-1}^{n+1}+a_{5} \\
i=1, \cdots, L_{c 0} \quad j=1, \cdots, N_{c v}
\end{gathered}
$$

where

$$
\begin{aligned}
& a_{1}=\frac{k_{x} \delta t}{\rho c_{p} \delta \tau \delta x_{\tau}} \\
& a_{2}=\frac{k_{x} \delta t}{\rho c_{p} \delta x \delta x_{l}} \\
& a_{3}=\frac{k_{z} \delta t}{\rho c_{p} \delta z \delta z_{t}} \\
& a_{4}=\frac{k_{z} \delta t}{\rho c_{p} \delta z \delta z_{b}} \\
& a_{5}=\frac{\rho_{\tau}\left(1-\nu_{f}^{(n)}\right) H_{R}\left(\frac{d \alpha}{d}\right)^{(n)} \delta t}{\rho c_{p}}
\end{aligned}
$$

$L_{c \nu}$ and $N_{c \nu}$ are the numbers of control volumes in the $x$ and $z$ directions, respectively (Figure 9 ). $\delta x, \delta x_{r}, \delta x_{l}, \delta$ $z, \delta z_{t}$ and $\delta z_{b}$ are shown in Figure 9. $\delta t$ is the time step size.

The $u_{i=1, j}^{n+1}$ and $u_{i, j-1}^{n+1}$ on the right-hand side of Equation (13) have all previously been calculated during the same time step $(n+1)$. The following expressions are used to describe the boundary conditions for the solution (boundary nodes)

$$
\begin{gathered}
u_{i, 0}^{n+1}=u_{0, j}^{n+1}=T_{a}^{n+1} \\
u_{i, N_{\mathrm{ev}}+1}^{n+1}=u_{\overline{i_{c u}}}+\mathbf{i} i, j=T_{a}^{n}
\end{gathered}\left\{\begin{array}{l}
i=1, \cdots, L_{c v} \\
j=1, \cdots, N_{c u}
\end{array}\right.
$$

Similarly, suppose $v_{t, j}$ is the pseudo-temperature solution of Equation (1) in the backward sweep. The final expression for $v_{t, i}$ at time step $t+\delta t$ for an interior node during the backward sweep can be obtained as /8/ 


$$
\begin{gathered}
\left(1+a_{1}+a_{3}\right) v_{i, j}^{n+1}=\left(1-a_{2}-a_{4}\right) v_{i, j}^{n}+a_{1} v_{i-1, j}^{n+1}+ \\
a_{2} v_{i-1, j}^{n}+a_{3} v_{i, j+1}^{n+1}+a_{4} v_{i, j-1}^{n+1}+a_{5} \\
i=L_{e v}, \cdots, 1 \quad j=\ddot{i}_{=1}^{*}, \cdots, 1
\end{gathered}
$$

The $v_{i+1, j}^{n+1}$ and $v_{i, j+1}^{n+1}$ on the right-side of Equation (16) are those previously computed during the same time step $(n+1)$. The boundary nodes for the solution of backward sweep equation are

$$
\begin{gathered}
v_{i, 0}^{n}=v_{0, j}^{n}=T_{a}^{n} \\
v_{i, N_{e v+1}^{n+1}}^{n+1}=v_{L_{e v}+1, j}^{n+1}=T_{a}^{n+1}
\end{gathered}\left\{\begin{array}{l}
i=i_{z=;} \cdots, 1 \\
j=N_{c v}, \cdots, 1
\end{array}\right.
$$

The temperature at each control volume at the new time level can be calculated as

$$
T_{i, j}^{n+1}=\frac{1}{2}\left(u_{i, j}^{n+1}+v_{i, j}^{n+1}\right)
$$

The discretization equation for two-dimensional flow can be obtained from the heat discretized equation, eliminating the heat generation source term $\left(a_{5}=0\right.$ ). Denoting $u$ and $v$ to represent pseudo-pressure in this case, for the forward sweep, it can be written /8/

$$
\begin{aligned}
& \left(1+a_{2}+a_{4}\right) u_{i, j}^{n+1}=\left(1-a_{1}-a_{3}\right) u_{i, j}^{n}+ \\
& a_{1} u_{i+1, j}^{n}+a_{2} u_{i-1, j}^{n+1}+a_{3} u_{i, j+1}^{n}+a_{4} u_{i, j-1}^{n+1} \\
& i=1, \cdots, L_{c e} \quad j=1, \cdots, N_{c z}
\end{aligned}
$$

where

$$
\begin{aligned}
a_{1} & =\frac{s_{x}}{\mu} \frac{\delta t}{m_{v} \delta x \delta x_{r}} \\
a_{2} & =\frac{s_{x}}{\mu} \frac{\delta t}{m_{v} \delta x \delta x_{l}} \\
a_{3} & =\frac{s_{z}}{\mu} \frac{\delta t}{m_{v} \delta z \delta z_{t}} \\
a_{4} & =\frac{s_{z}}{\mu} \frac{\delta t}{m_{v} \delta z \delta z_{b}}
\end{aligned}
$$

The boundary nodes are

$$
\begin{aligned}
& u_{i, 0}^{n+1}=u_{0, j}^{n+1}=P_{b c}^{n+1} \quad\left\{i=1, \cdots, L_{c v}\right. \\
& u_{a, N_{c+1}+1}^{n}=u_{L_{c o+1}+1, j}^{n}=P_{b c}^{n}\left\lfloor j=1, \cdots, N_{c o}\right.
\end{aligned}
$$

Similarly, for an interior node during the backward sweep, it can be shown that /8/

$$
\begin{gathered}
\left(1+a_{1}+a_{3}\right) v_{i, j}^{n+1}=\left(1-a_{2}-a_{4}\right) v_{i, j}^{n}+ \\
a_{1} v_{i+1, j}^{n+1}+a_{2} v_{i-1, j}^{n}+a_{3} v_{i, j+1}^{n+1}+a_{4} v_{i, j-1}^{n \cdot} \\
i=L_{c v}, \cdots, 1 \quad j=N_{c v}, \cdots, 1
\end{gathered}
$$

The boundary nodes for the solution of the backward sweep equation are

$v_{i, 0}^{n}=v_{0, j}^{n}=P_{b c}^{n}$
$v_{i, N_{c v}+1}^{n+1}=v_{L_{e v}+1, j}^{n+1}=P_{b c}^{n+1}$$\left\{\begin{array}{l}i=L_{c o}, \cdots, 1 \\ i=N_{c v}, \cdots, 1\end{array}\right.$

The pressure at each control volume at the new time level can be calculated as

$$
P_{i, j}^{n+1}=\frac{1}{2}\left(u_{i, j}^{n+1}+v_{i, j}^{n+1}\right)
$$

The discretization equations for one-dimensional through-the-thickness can be simply obtained from Equations (13), (16), (19), and (22) by eliminating those terms which represent the $x$ direction. For more details about the solution and solution techniques, see references (7) and (8).

\section{EXPERIMENTAL AND SIMULATION RESULTS}

The experimental results should be compared with the simulation results in order to verify the process models. After verification of the models and numerical solutions, simulation can be used to study thick laminate behavior during the cure process.

Two computer codes based on the discretization equations (Equations (13), (16), (19), and (22)) were developed for one-dimensional and two-dimensional simulation studies.

\subsection{Composite Physical Properties}

The physical properties of the composite are considered to be functions of the fiber volume fraction $v_{f}$. This type of calculation provides more accurate results in the simulation. Due to the nonuniform resin flow through the thickness, there would be a fiber volume fraction 
gradient, resulting in different physical properties at different locations. Therefore, composite physical properties should be expressed in terms of fiber volume fraction and its constituent physical properties.

The prepreg specifications as well as kinetic and viscosity parameters for Hercules AS4/3501-6 are shown in Table 3 . The kinetic and viscosity equations are given by Equations (5) and (9), respectively.

Two sets of parameters are given for the kinetic equation by Martinez /5/ and Lee et al. 121/. The Martinez parameters for the kinetic equation provide better simulation results for the temperature in comparison with the experimental results. The Martinez parameters are chosen for the simulation (Table 3).

Different curing kinetic parameters would result in different calculated values for the degree of cure $\alpha$.
Viscosity parameters reported by Lee et al. /21/ are obtained based on the kinetic parameters calculated by them. Using the Martinez kinetic parameters, the values of the constants $U, d$, and $\mu_{\infty}$ would be expected to change. However, comparison between viscosities calculated by simulation and those measured by Carpenter (see references $/ 6 /$ and $/ 21 /$ ), as shown in Figure 10, show that the combination of Lee viscosity parameters and Martinez kinetic parameters predicts viscosity well. Therefore, Lee viscosity parameters are used for simulation without any correction (Table 3 ).

Composite heat capacity $c_{p}$, density $\rho$, and thermal conductivity in the fiber direction $k_{z}$ are calculated using the rule of mixtures. Thermal conductivity in the $z$ direction is calculated using the relation derived by Springer and Tsai $122 \%$. The relation proposed by Springer and Tsai to calculate thermal conductivity

Table 3

Material properties of Hercules AS4/3501-6.

\begin{tabular}{|c|c|c|}
\hline Fiber radius & $r_{f}$ & $3.5 \times 10^{-6} \mathrm{~m}$ \\
\hline Fiber density & $\rho_{f}$ & $1.79 \times 10^{3} \frac{\mathrm{kg}}{\mathrm{m}^{3}}$ \\
\hline Specific heat of fiber & $c_{p f}$ & $7.12 \times 10^{2} \frac{\mathrm{J}}{\mathrm{kg} 0^{\circ}} \mathrm{R}$ \\
\hline Thermal conductivity of fiber & $k_{f}$ & $26 \frac{W}{m^{\circ} h}$ \\
\hline Resin density & $\rho_{r}$ & $1.26 \times 10^{3} \frac{\mathrm{kg}}{\mathrm{m}^{3}}$ \\
\hline Specific heat of resin & $c_{p r}$ & $1.26 \times 10^{3} \frac{\mathrm{J}}{\mathrm{kg} \sigma^{\circ} \mathrm{R}}$ \\
\hline Thermal conduetivity of resin & $k_{\tau}$ & $0.16 i \frac{\mathrm{W}}{\mathrm{m}^{\circ} \mathrm{h}}$ \\
\hline Pre-exponential factor & $A_{1}$ & $5.88 \times 10^{9} \mathrm{~min}^{-1}$ \\
\hline Pre-exponential factor & $A_{2}$ & $-3.906 \times 10^{9} \mathrm{~min}^{-1}$ \\
\hline \multirow[t]{2}{*}{ Pre-exponential factor } & \multirow[t]{2}{*}{$A_{3}$} & $T \leq 146^{\circ} \mathrm{C} \quad 1.5 T \times 10^{15} \mathrm{man}^{-1}$ \\
\hline & & $T>146^{\circ} \mathrm{C} 1.96 \times 10^{5} \mathrm{~min}^{-1}$ \\
\hline Activation energy & $\Delta E_{1}$ & $8.43 \times 10^{4} \frac{\mathrm{J}}{\mathrm{mol}}$ \\
\hline Activation energy & $\Delta E_{2}$ & $8.03 \times 10^{4} \frac{\mathrm{J}}{\mathrm{mol}}$ \\
\hline \multirow[t]{2}{*}{ Activation energy } & \multirow[t]{2}{*}{$\Delta E_{3}$} & $T \leq 146^{\circ} \mathrm{C} \quad 13.6 \times 10^{4} \frac{\mathrm{J}}{\mathrm{mol}}$ \\
\hline & & $T>146^{\circ} \mathrm{C} \quad 5.66 \times 10^{4} \frac{\mathrm{J}}{\mathrm{mod}}$ \\
\hline Heat of reaction & $H_{R}$ & $4.73 \times 10^{5} \frac{\mathrm{J}}{\mathrm{kg}}$ \\
\hline Activation energy for viscosity & $U$ & $9.08 \times 10^{4} \frac{\mathrm{J}}{\mathrm{mol}}$ \\
\hline Viscosity constant & $\mu_{\infty}$ & $7.93 \times 10^{-14}$ Pa.s \\
\hline Viscosity constant & $d$ & 14.1 \\
\hline
\end{tabular}



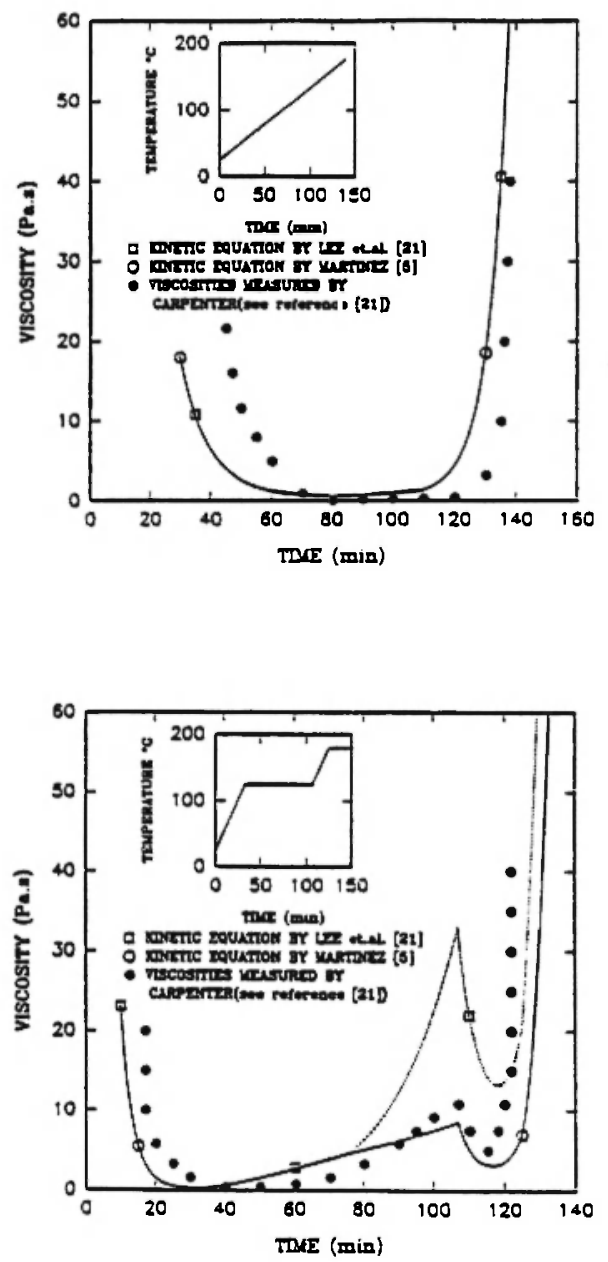

Fig. 10: (a) and (b) Comparison between the viscosities measured by Carpenter and the predicted viscosities. The insets show the applied temperature profile (dynamic heating).

normal to the fibers $k_{z}$ for square packing is $/ 22 /$

$$
\begin{aligned}
& \frac{k_{z}}{k_{r}}=\left(1-2 \sqrt{\frac{\nu_{f}}{\pi}}\right)+ \\
& \frac{1}{D}\left[\pi-\frac{4}{\sqrt{1-\left(\frac{\bar{\nu}_{-1} \nu_{f}}{\pi}\right)}} \arctan \frac{\sqrt{1-\left(\frac{D^{2} \nu_{f}}{\pi}\right)}}{1+D \sqrt{\frac{\pi_{f}}{\pi}}}\right]
\end{aligned}
$$

and

$$
D=2\left(\frac{k_{r}}{k_{f}}-1\right)
$$

$k_{r}$ and $k_{f}$ are thermal conductivities of resin and fiber, respectively.
Permeability is determined according to the Kozeny-Carman equation which can be simply written as $/ 23$ /

$$
s_{i}=\frac{\hat{r_{f}}}{4 K_{i}} \frac{\left(1-\nu_{f}\right)^{3}}{\nu_{f}^{2}}
$$

where $r_{f}$ is the fiber radius and $K_{i}$ is the Kozeny constant. $i$ can be $x, y$ or $z$. $s_{x}$ is permeability along the fiber direction and is called Axial Permeability. Transverse Permeability $\left(s_{z}\right)$ represents the permeability in the direction perpendicular to the fibers. For the simulation, $K_{x}$ and $K_{z}$ are assumed to be 0.3 and 6.0 , respectively.

\subsection{One-dimensional Results}

The tooling setup. used for the simulation is shown in Figure 11. The polyester bleeder thickness measured after the experiment was $5.5 \mathrm{~mm}$, of which $3.8 \mathrm{~mm}$ was filled with resin and the rest was dry. The polyester physical properties used in the simulation are given in Table $4 / 24,25 /$. The calculated bleeder fiber volume fraction was 0.3 .

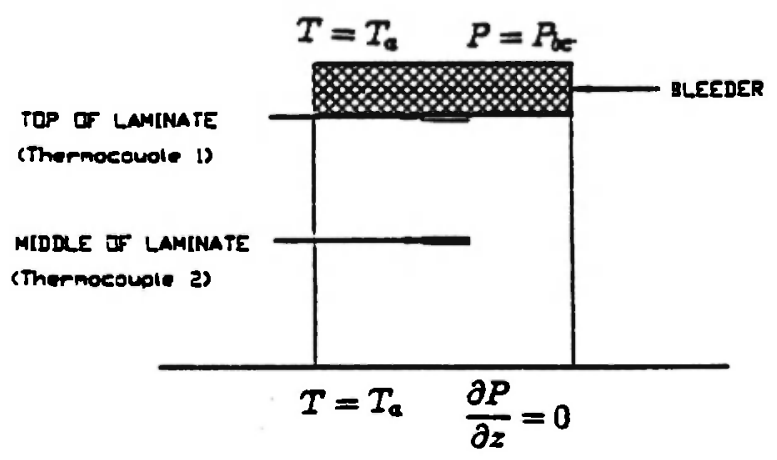

Fig. 11: Tooling setup used for simulation (onedimensional analysis and 330-layer laminate).

Table 4

Typical physical properties of polyester.

\begin{tabular}{|l|l|}
\hline Density & $1300 \frac{\mathrm{kg}}{\mathrm{m}^{\mathrm{j}}}$ \\
\hline Specific Heat & $1600 \frac{\mathrm{J}}{\mathrm{kg} \cdot \mathrm{R}}$ \\
\hline Thermal Conductivity & $0.17 \frac{\mathrm{W}}{\mathrm{m} \cdot \mathrm{K}}$ \\
\hline
\end{tabular}


Bleeder physical properties are calculated based on the laminate compaction during curing. It is assumed that the resin flowing to the bleeder is distributed uniformly throughout the $3.8 \mathrm{~mm}$ bleeder plies. Bleeder density and specific heat are calculated using the rule of mixtures. It is assumed that the initial bleeder thermal conductivity $\left(k_{b i}\right)$ is $0.01 \frac{\dddot{m}}{m+\hat{n}}$ (typical thermal conductivity for insulating materials), and during the consolidation stage it reaches its final value $\left(k_{b}\right)$ of $0.17 \frac{\dddot{w}}{m^{\circ} K}$ (the polyester and the epoxy 3501-6 have almost the same thermal conductivity). The variation of bleeder thermal conductivity can be expressed as a function of laminate compaction. The following equation is used for the simulation

$$
k_{b}=k_{b i}+\frac{\left(k_{b f}-k_{b i}\right) L_{i}}{L_{f}}
$$

where $k_{h}$ is the bleeder thermal conductivity. $L_{t}$ is the laminate thickness reduction at each time step and $L_{f}$ is the total laminate thickness reduction after curing.

Simulation and experimental results for temperature measurement at top and middle of the laminate are shown in Figure 12. The predicted temperatures are in good agreement with the measured temperatures, except in the first dwell period. The peak temperatures in the second dwell period are almost the same for both experiment and simulation.

There are two possibilities to explain the mismatch between actual and predicted temperature. The thermal properties of the polyester bleeder were not given by the manufacturer and, therefore, they were taken as typical properties obtained from handbooks (Table 4). Simulation shows that among the bleeder physical properties, initial thermal conductivity has more effect in the simulation. Different initial thermal conductivities were examined $(0.001$ to 0.3$)$. However, a mismatch between the measured and predicted temperatures was always observed. Therefore, it is not the only reason for a mismatch.

Examination of Figure 12 suggests that the kinetic equation has to be improved. The rate of reaction predicted by the kinetic equation is higher than the actual reaction. In the simulation, the reaction proceeds faster than the actual reaction, generating heat faster. The generated heat does not have enough time to reach

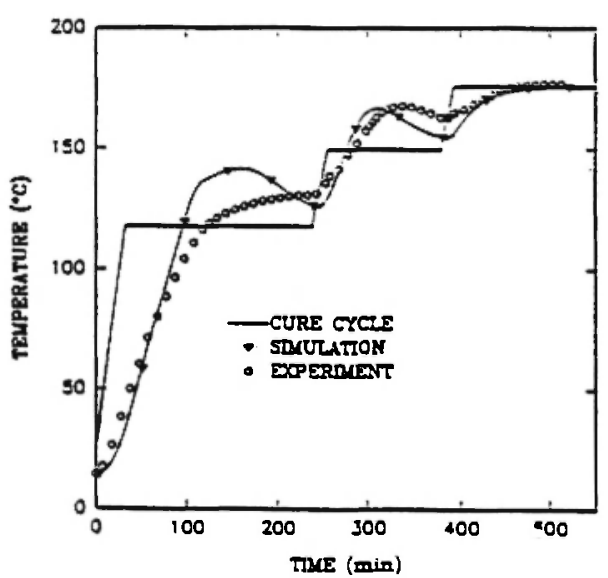

(a)

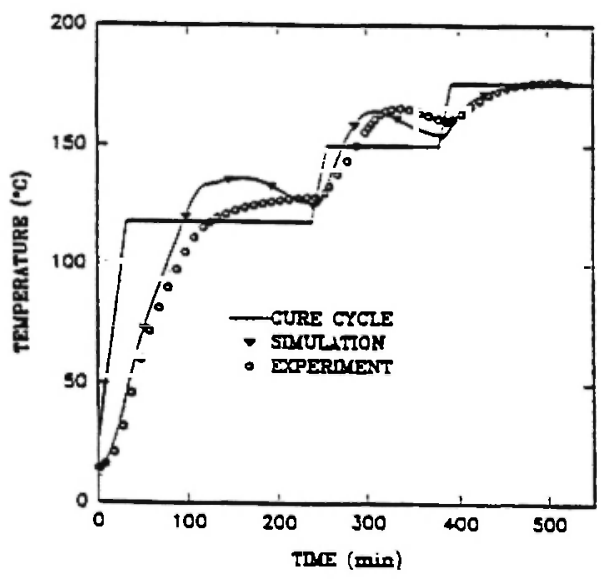

(b)

Fig. 12: Comparison between the measured and predicted temperature for one-dimensional analysis and 330-layer laminate. (a) Top of the laminate close to the bleeder; (b) Middle of the laminate.

the surface and to dissipate. The internal energy increases, raising the laminate temperature. Due to the lower bleeder thermal conductivity at the first ramp and dwell period of the cure cycle, a higher rate of heat generation in the simulation causes a higher mismatch between the predicted and actual temperature. It can be concluded that the kinetic equation proposed by Lee $e t$ al. $/ 21 /$ and modified by Martinez /5/ for epoxy 3501-6 overestimates the rate of chemical reaction and should be improved.

Both experiment and simulation show that the temperature distribution through-the-thickness is not symmetric (Figure 13). In fact, due to the insulating 


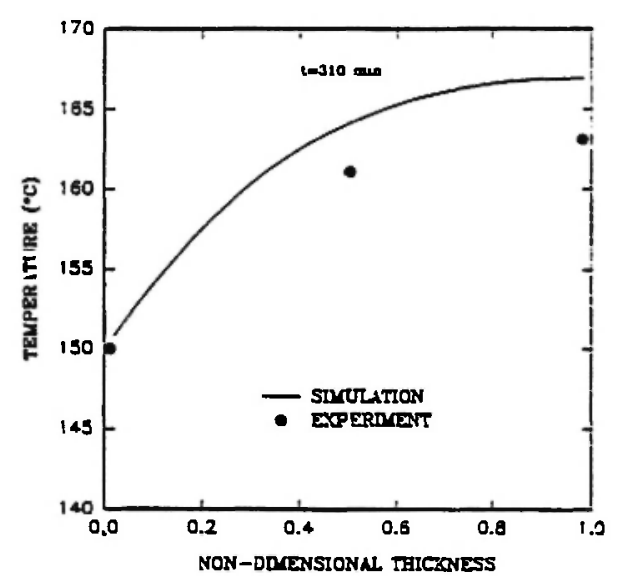

Fig. 13: Temperature distribution through-thethickness (one-dimensional analysis and 330-layer laminate).

behavior of bleeder plies, the temperature at the top of the laminate is higher than the temperature in the middle.

The simulation results for the laminate compaction are shown in Figure 14. The measured thickness after curing was $45 \mathrm{~mm}$, which is in good agreement with simulation. The predicted and calculated fiber volume fraction distribution through-the-thickness is shown in Figure 15. The fiber distribution is not uniform. A fully compacted thick laminate cannot be fabricated by this technique. Good agreement between predicted and calculated fiber volume fraction is obtained. The maximum error (in the middle of the laminate) is about eight percent.

\subsection{Two-dimensional Results}

As explained before, this experiment was designed to have two-dimensional heat transfer and onedimensional resin flow. However, both heat transfer and resin flow were two-dimensional during the experiment. Simulation is done for this case. The tooling setup used in the simulation is shown in figure 16. Based on the laminate cross-section examination, one layer of resin with thickness $0.5 \mathrm{~mm}$ was assumed at the laminate sides in the simulation. The bleeder thickness was $5 \mathrm{~mm}$ and all the bleeders were filled with resin. Bleeder thermal conductivity is calculated using Equation (28). The Kozeny constant for

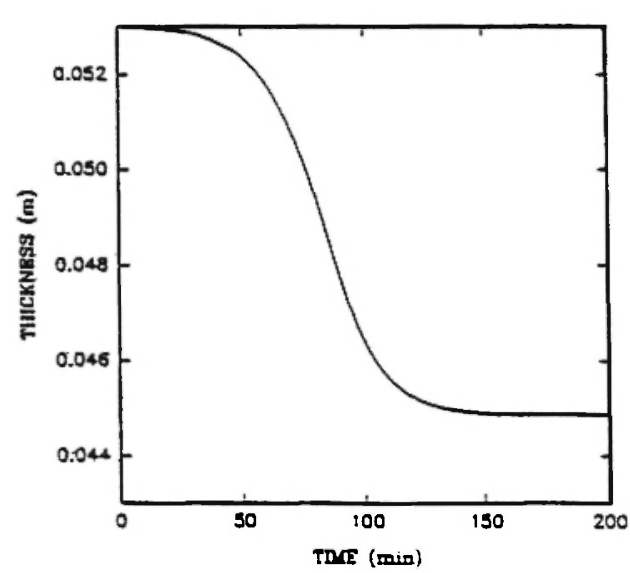

Fig. 14: Laminate compaction evolution (onedimensional analysis and 330-layer laminate).

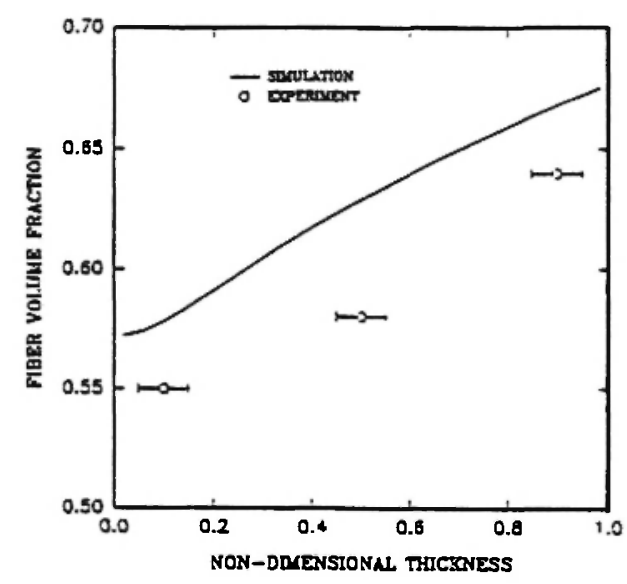

Fig. 15: Fiber volume fraction distribution throughthe-thickness (one-dimensional analysis and 330-layer laminate).

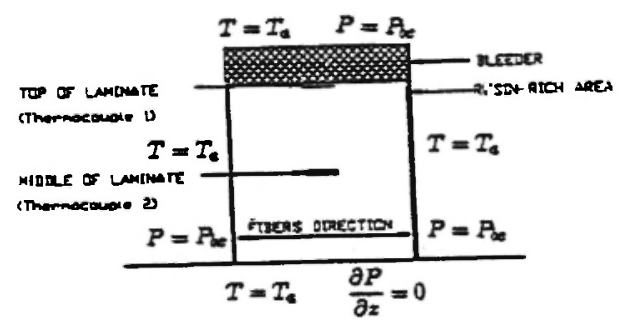

Fig. 16: Tooling setup used for simulation (twodimensional analysis and 330-layer laminate). 
permeability calculation along the fibers is assumed to be 0.3 . The predicted and measured temperatures are shown in Figure 17. Again, it seems that the kinetic equation overestimates the rate of reaction.

\subsection{Prebleeding Results}

Two simulations are required to study the prebleeding process. First, the prebleeding cure cycle is applied to the sublaminates. The same tooling setup as shown in Figure 11 was used. The simulation shows that, at the end of curing the sublaminates, the degree of cure is 0.3 and each sublaminate is fully compacted with the
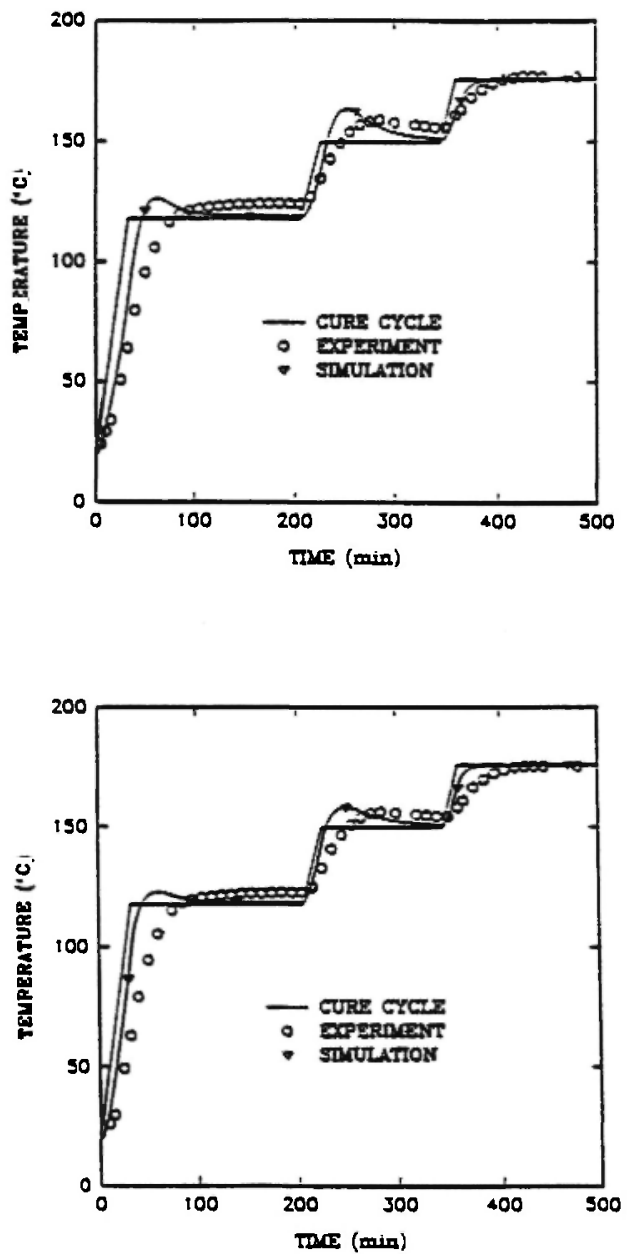

Fig. 17: Comparison between the measured and predicted temperature for two-dimensional analysis and 330-layer laminate. (a) Top of the laminate; (b) Middle of the laminate. uniform fiber volume fraction equal to 0.68 . Since there is no compaction allowed in the final cure cycle, the laminate final fiber volume fraction is 0.68 . This value for $v_{f}$ and those obtained by experiment (Table 2) are in good agreement.

The next simulation is performed using the modified cure cycle for final curing as explained before. Initial conditions are

$$
\begin{aligned}
& \alpha_{0}=0.4 \\
& v_{f}=0.68
\end{aligned}
$$

No compaction is allowed. Tooling setup shown in Figure 11 is used with $0.5 \mathrm{~mm}$ breather thickness. The actual and predicted temperature in the middle of the laminate is shown in Figure 18. As before, due to the higher rate of reaction in simulation, a mismatch between the predicted and actual temperature is observed.

\subsection{Bleeder Effect}

When consolidation is allowed during curing, bleeder plies are required in the tooling setup to absorb the extra resin. Glass and polyester cloths are two materials commonly used as bleeders $126 \%$. Both glass and polyester have a low thermal conductivity which can have a significant effect on the curing process, particularly for thick composites.

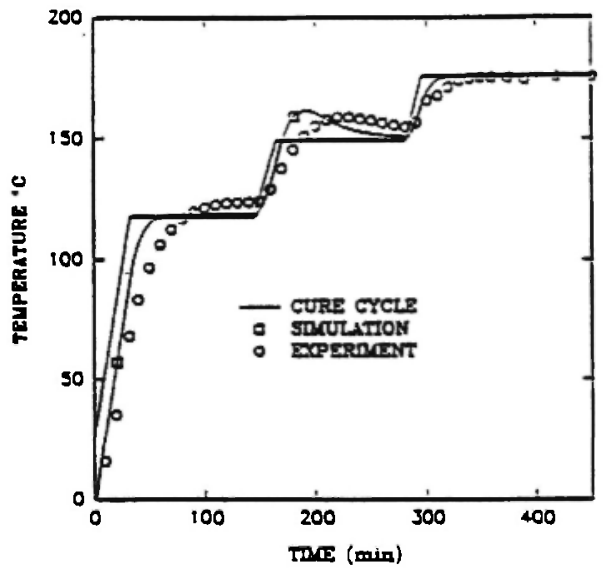

Fig. 18: Comparison between the measured and predicted temperature in the middie of the laminate (prebleeding experiment and 320layer laminate). 
The tooling setup shown in Figure 11 is used for the simulation. The polyester bleeder has a fiber volume fraction equal to 0.3 and its thickness is assumed to be $11.5 \mathrm{~mm}$, just enough bleeder material to absorb $8 \mathrm{~mm}$ resin produced by laminate compaction. If $v_{f}$ is the bleeder fiber volume fraction and $L_{t}$ is the total laminate thickness reduction after curing, the bleeder thickness $\left(t_{b}\right)$ for that compaction can be obtained using the following expression

$$
t_{b}=\frac{L_{t}}{1-\nu_{f}}
$$

The bleeder thermal conductivity is calculated using Equation (28).

The temperature history at the top and middle of the $5 \mathrm{~cm}$ thick laminate, considering the insulating effect of the bleeders, is shown in Figures 19 and 20. The low thermal conductivity of the bleeder as well as the bleeder thickness create some problems. At the beginning of curing, the bleeders are empty and their thermal conductivities are very low, delaying heat flow to the laminate. When maximum reaction takes place and heat is generated rapidly, the bleeder again prevents rapid heat dissipation, increasing the laminate temperature. Figure 21 shows the temperature distribution through-the-thickness which is not symmetric. Maximum temperature occurs on the top of the laminate, close to the bleeder side. Figure 22 represents the laminate compaction. The bleeder prevents heat from penetrating inside the laminate rapidly and delays laminate compaction. However, it does not greatly affect the final laminate compaction.

\section{CONCLUSION}

A one-dimensional through-the-thickness experiment on a thick composite (330-layer) was performed. The bleed setup was used. Two problems were found, the temperature overshoot at the second dwell temperature and the incomplete through-the-thickness consolidation. The temperature on top of the laminate was observed to be higher than in the middle of the laminate. Therefore, the maximum temperature may not occur in the middle of the laminate.

To reduce the temperature overshoot, a two-

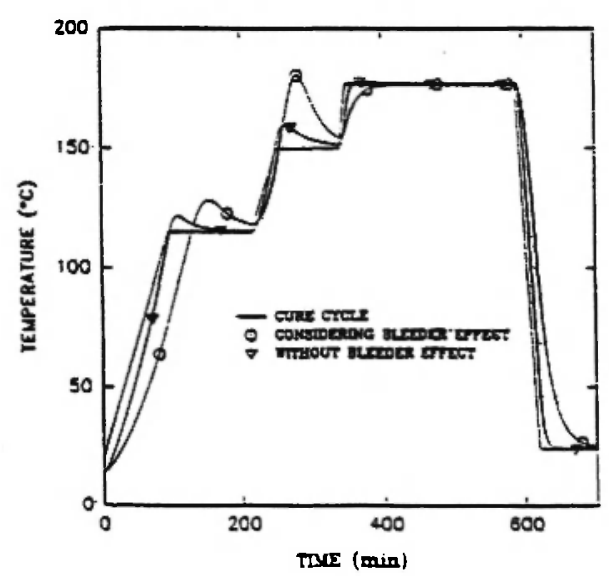

Fig. 19: Predicted temperature in the middle of the 5 cm thick laminate (bleeder effect).

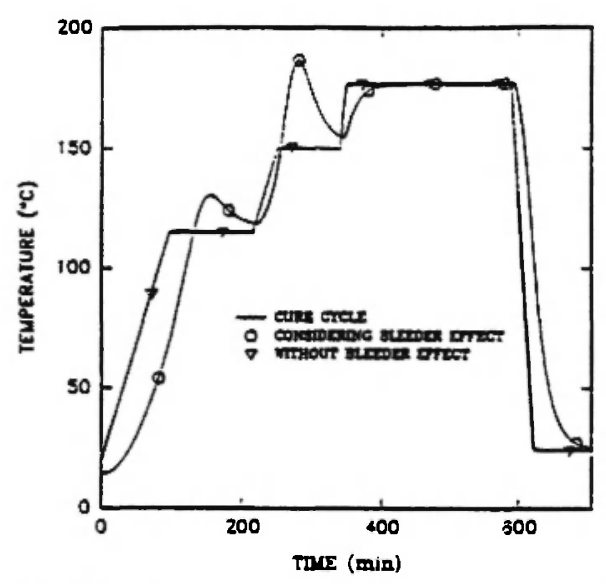

Fig. 20: Predicted temperature at the top of the $5 \mathrm{~cm}$ thick laminate (bleeder effect).

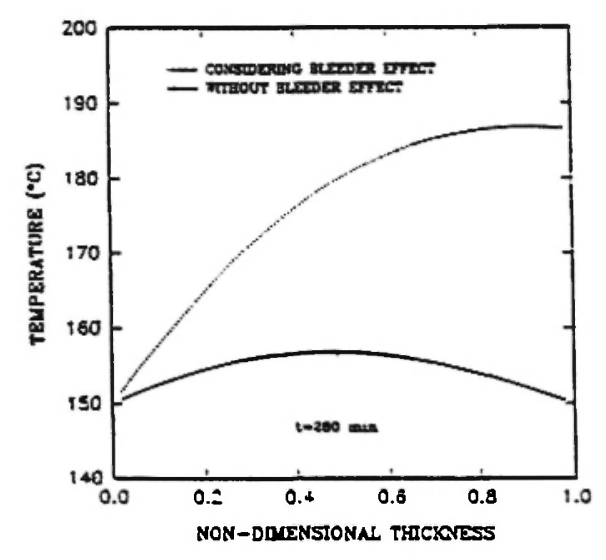

Fig. 21: Temperature distribution through-thethickness of the $5 \mathrm{~cm}$ thick laminate (bleeder effect). 


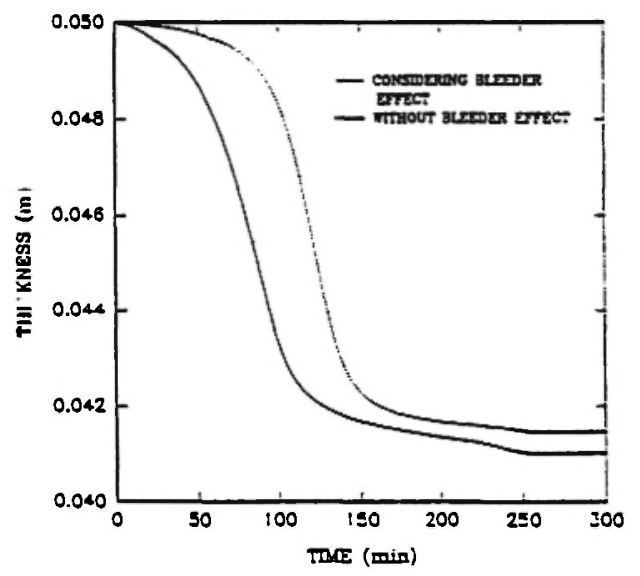

Fig. 22: Compaction of the $5 \mathrm{~cm}$ thick laminate (bleeder effect).

dimensional experiment was designed and performed. The bleed setup was used. The two-dimensional curing decreases the temperature overshoot as well as the cure cycle time. Therefore, one can take advantage of the heat transfer through the thick laminate sides.

A prebleeding experiment was designed and performed to achieve complete through-the-thickness consolidation. The thick laminate was divided into thin sublaminates. After prebleeding the sublaminates using a bleed setup, the sublaminates were put together and completely cured (using no-bleed setup). Uniform compaction was obtained.

The heat conduction equation and the kinetic, viscosity, and flow (squeezed sponge model) equations were solved simultaneously. Two computer codes for one- and two-dimensional situations have been developed. Good agreement between simulation and experiment was observed.

The bleeder effect was studied by simulation. It was shown that the insulative behavior of the bleeder plies delays heat flow to the center region of the laminate, increases the cure cycle time and delays compaction. It also causes a higher temperature overshoot inside the laminate. Therefore, the bleeder has a negative effect on the curing process.

No bleeder plies were used in the final stage of the prebleeding technique. Full compaction and uniform fiber distribution were achieved by this technique. Therefore, it can be concluded that prebleeding is the best way to fabricate thick laminates.

\section{REFERENCES}

1. A.C. Loos and G.S. Springer, Journal of Composite Materials, 17, 135-169 (1983).

2. A.R. Mallow, F.R. Muncaster and F.C. Campbell, Proceedings of the American Society for Composites First Technical Conference, Dayton, OH, 1986; pp. 171-186.

3. L.N. Hjellming and J.S. Walker, Journal of Composite Materials, 23, 1048-1064 (1989).

4. T.A. Bogetti and J.W. Gillespie, Journal of Composite Materials, 25, 239-273 (1991).

5. G.M. Martinez, Chemical Engineering Science, 46(2), 439-450 (1991).

6. T.E. Twardowski, S.E. Lin and P.H. Geil, Journal of Composite Materials, 27(3), 216-250 (1993).

7. M. Hojjati and S.V. Hoa, Composites Manufacturing, 5(3), 159-169 (1994).

8. M. Hojjati, "Curing of Thick Thermosetting Composites: Experiment, Simulation, and Scaling", Ph.D. Dissertation, Concordia University, Montreal, Quebec, Canada, 1994.

9. R. Pitchumani and S. Yao, Journal of Composite Materials, 27(6), 613-636 (1993).

10. M. Hojjati and S.V. Hoa, Journal of composite Materials, in press, 1995.

11. T.G. Gutowski, SAMPE Quarterly, 16(4), 58-64 (1985).

12. T.G. Gutowski, T. Morigaki and Z. Cai, Journal of Composite Materials, 21, 172-188 (1987).

13. T.G. Gutowski, Z. Cai, S. Bauer, S. Boucher, S. Kingery and S. Wineman, Journal of Composite Materials, b21, 650-669 (1987).

14. R Dave, J.L. Kardos and M.P. Dudukovic, Proceedings of the American Society for Composites First Technical Conference, Dayton, $O H$, , 1986; pp. 137-153.

15. R. Dave, J.L. Kardos and M.P. Dudukovic, Polymer Composites, 8(1), 29-38 (1987).

16. R. Dave, J.L. Kardos and M.P. Dudukovic, Polymer Composites, 8(2), 123-132 (1987).

17. R. Dave, Journal of Composite Materials, 24, 2241 (1990).

18. G.D. Smith and A. Poursartip, Journal of Composite Materials, 27(17), 1695-1711 (1993).

19. L.A. Carlsson and R. Byron Pipes, Experimental 
Characterization of Advanced Composite Materials, Prentice-Hall, N.J., 1987.

20. M.N. Ozisik, Heat Conduction, John Wiley and Sons, New York, 1980.

21. II Lee Woo, A.C. Loos and G.S. Springer, Journal of Composite Materials, 16, 510-520 (1982).

22. G.S. Springer and S.W. Tsai, Journal of Composite Materials, 1, 166-173 (1967).

23. B.T. Astrom, R.B. Pipes and S.G. Advani, Journal of Composite Materials, 26(9), 13511373 (1992).
24. B.W. Rosen and N.F. Dow, "Overview of composite materials analysis and design", in: Engineering Materials Handbook, Volume 1 Composites. ASM International, 1987.

25. Anonymous, "Low temperature thermoset matrix composites", in Engineering Materials Handbook, Volume 1 - Composites. ASI.: International, 1987.

26. TW Gann and E.R. Crilly, "Preparation for cure", in: Engineering Materials Handbook, Volume 1 Composites. ASM International, 1987. 
